\title{
Ideas en movimientos: actores, discursos y agencia en el Buenos Aires del siglo XIX
}

Ideas in movements: actors, speeches and agency in the 19th century Buenos Aires

\author{
Mariano Di Pasquale \\ CONICET/Instituto de Estudios Históricos-UNTREF, Argentina \\ mariano.dipasquale@gmail.com \\ Guillermina Guillamon \\ CONICET/Instituto de Estudios Históricos-UNTREF, Argentina \\ guillermina.guillamon@gmail.com
}

\begin{abstract}
Resumen:
El presente dossier introduce a un conjunto de artículos que reflexionan sobre el potencial que tienen los estudios de casos para poner en un primer plano las dimensiones que posibilitan ver a los sujetos en acción. Asimismo, los trabajos permiten indagar en tres dimensiones creciente de interés en la historiografía local: el despliegue de las trayectorias biográficas, la circulación y apropiación de saberes y las prácticas y, por último, los cursos de acción desarrollados por los sujetos en un largo y complejo siglo XIX. Palabras Clave: Trayectorias, Saberes e ideas, Circulación y apropiación, Cursos de acción, Buenos Aires, Siglo XIX.
\end{abstract}

\begin{abstract}
:
This dossier presents a set of articles that show the potential of case studies to bring to the forefront the dimensions that allow you to see the subjects in action. Likewise, the works allow us to investigate in three growing dimensions of interest in local historiography: the deployment of biographical trajectories, the circulation and appropriation of knowledge and practices and, finally, the courses of action developed by the subjects in a long and complex century XIX.
\end{abstract}

KEYwORDs: Trajectories, Knowledge and ideas, Circulation and appropriation, Courses of action, Buenos Aires, 19th century.

El presente dossier se enmarca en la intersección de tres dimensiones de análisis de creciente interés por parte de la historiografía local: el despliegue de las trayectorias biográficas -tanto individuales como de elencos colectivos más amplios-, la circulación y apropiación de saberes y las prácticas y, por último, las acciones desarrolladas por los sujetos. Asimismo, este cruce está anclado en un proceso de largo aliento, a saber: la circulación y producción de ideas y conocimientos que, de forma progresiva, serán apropiados y asociados a determinados campos de saberes y de acción en el Buenos Aires del siglo XIX. Dicho carácter procesual invita a desarrollar un análisis que priorice las continuidades, solapamientos y tensiones y que, en consecuencia, inserte los casos de estudio en un marco temporal de larga duración. Por ello, los trabajos de este dossier parten de pensar al siglo XIX como un clima de época, como un espacio temporal más amplio, en vinculación tanto con el siglo XVIII- específicamente con el período tardocolonial- como con los inicios de siglo XX.

En este contexto, surgen una serie de interrogantes que atraviesan y vinculan a los artículos aquí presentes: ¿Cómo reconstruir el contexto priorizando un análisis del sentido que los actores le otorgan a sus acciones en relación a la apropiación de saberes? ¿Cómo reponer las posiciones que asumieron en las diversas dimensiones de sus prácticas? ¿Con qué herramientas metodológicas reconstruir e historizar las trayectorias y las experiencias de los sujetos? Partiendo de estas preguntas teórico-metodológicas, los trabajos del dossier reflexionan sobre el potencial que tienen los estudios de casos en el campo de las ciencias sociales 
-particularmente desde el campo historiográfico- y de cómo este tipo de enfoques ponen en un primer plano las dimensiones que nos posibilitan ver a los sujetos en acción. ${ }^{1}$

Tal como ha mostrado la microhistoria, el estudio de las trayectorias biográficas permite invertir la escala de análisis y reconstruir contextos y procesos de más largo alcance, anulando la diferencia entre micro y macro y estableciendo nuevas explicaciones para los cambios estructurales. ${ }^{2}$ Permite reconstruir aquello que se ha denominado sistema de contexto: las incertidumbres de las elecciones, que descomponen las realidades articuladas en un solo tiempo, restituyen las múltiples situaciones en las cuales el sujeto pudo reorganizar su experiencia y configurar su estrategia pese a la rigidez de las estructuras políticas o ideológicas (Bensa, 2015, p. 60). De este modo, indagar en torno a qué hicieron los actores nos conduce a la descripción del mundo que habitaron: es en la propia acción en donde se construye el contexto en el que dichas acciones cobran sentido (Garzón Rogé, 2017, pp. 17-20).

Más específicamente, nos interesa situar la atención en el curso de las acciones en relación con la circulación y apropiación de saberes para, a partir de allí, reconstruir la realidad social y sus múltiples dimensiones. En este sentido, un concepto clave en este dossier es el término de apropiación en tanto "(...) una historia social de los usos e interpretaciones, relacionados con sus determinaciones fundamentales e inscritos en las prácticas específicas que los producen" (Chartier, 1992, p. 53). Si bien los aportes de Chartier son consecuencia del abordaje de las prácticas de lectura en tanto construcción de sentido, esta apropiación -que supone mediadores y una cierta contingencia histórica- al tiempo que nos permite focalizar en la circulación y producción, nos posibilita hacer énfasis en la agencia de los sujetos en relación con los saberes y los objetos.

Siguiendo los aportes de Gilles Deleuze (1987) y Michel Foucault (2005), los saberes son producciones históricas resultado de las formas de organización de los conocimientos que no necesariamente están sistematizados y estabilizados. Un saber es el modo de hacer de una época. Ellos son el fruto de los modos de comprensión del conocimiento en sus delimitaciones sociales, políticas, culturales, religiosas o científicas. En cada campo de producción opera una lógica de producción y reproducción del conocimiento, unos rituales de apropiación y unos procesos de selección. Cada campo de producción del saber implica un conjunto de técnicas necesarias para la transmisión y apropiación del conocimiento. Al respecto, Pierre Bourdieu establece una diferenciación entre campo de producción y campo receptor en la circulación de saberes. Con ello, introduce el problema de las transferencias en la difusión de los textos y discursos. Demuestra el desfasaje temporal que suele producirse en el desplazamiento de uno a otro campo y los equívocos que este proceso representa. También, expone una serie de operaciones literarias como ser la traducción, la edición, las reimpresiones, etc. en las cuales los discursos que las atraviesan pueden re-direccionar el sentido y la intención del contexto de producción (Bourdie, 1993, pp. 159-172).

Ahora bien, una manera posible que tenemos para penetrar en los saberes es a través del discurso. El discurso, cuyo sustrato es el lenguaje, supone efectos activos sobre el medio social y, por lo tanto, según Quentin Skinner (1986) es fundamental entender esos actos de habla dentro de un escenario de relaciones lingüísticas para lograr percibir la intencionalidad del actor, qué acción emprendió éste al decir lo que decía en el contexto en que lo llevo a cabo. (Greville y Pocock, 1971; Burke, 2001). Pero desde la historia cultural, aparece una crítica que coincide en observar el problema que tiene asumir la realidad social como algo configurado exclusivamente por el lenguaje, el prestarle demasiada atención a los discursos y postergar las características de su comunicación, así como otros tipos de prácticas no discursivas. Esto sirve para recordar que los saberes están representados en objetos materiales como así también en las relaciones de poder.

En Las palabras y las cosas, Foucault (2003, pp. 48-52) ya indicaba que en todo periodo de la historia existían ciertas condiciones fundamentales de verdad, y que éstas impactaban en la conformación de un determinado discurso. En esta línea, es pertinente la aproximación de Steven Shapin y Simon Schaffer (2005, pp. 20-40) quienes observan que el proceso de construcción de una verdad siempre pone de manifiesto una construcción de poder. $\mathrm{O}$ para decirlo en otras palabras, que existe una íntima conexión entre el problema de la política y el problema del conocimiento. No hay posibilidad de separar la cuestión del conocimiento 
de la cuestión política porque es imposible separar el problema de la verdad de aquello que se hace con ella. Y el problema de qué se hace con la verdad (aquello que se toma como tal) es inmediatamente un problema de naturaleza política. La verdad más sencilla está constitutivamente vinculada a un orden moral que, por ejemplo, nos invita a decir la verdad. La cuestión de la verdad es inherente a la cuestión del poder porque cuando se difunde una verdad hay alguien que tiene la capacidad de gestionarla. Y esto es lo que sucede concretamente en los trabajos que aquí presentamos que buscan poner en diálogo la triada actores-saberesacciones en el Río de la Plata durante el siglo XIX. Es por ello que el presente Dosier pivoteará entre estos aspectos porque este tipo de aproximación, siguiendo a Pierre Rosanvallon, nos permite “...tener en cuenta todas las representaciones "activas" que orientan la acción, que limitan el campo de lo posible a través del campo de lo pensable y delimitan el marco de las controversias y los conflictos" (Rosanvallon, 2002, p. 46).

En suma, el conjunto de trabajos presentes en este dossier busca dar cuenta de un clima de época que, aunque fragmentado y nunca estable, emerge en el análisis de un conjunto de actores vinculados a diversas dimensiones de lo social. Lucas Angueira en "Las colecciones documentales de Segurola y Araujo y las representaciones del pasado en Buenos Aires (1780-1820)" analiza la práctica coleccionista con el objetivo de indagar tanto en un conjunto de cambios políticos (como la sociabilidad letrada) que comenzaba a operar en la Buenos Aires de ese período al tiempo que mostrar nexos con diversas pujas políticas que se producían en esa ciudad, en la región rioplatense, en la totalidad de la monarquía e incluso fuera de ella, con una clara continuidad tras el período de revolución y guerra.

En "Entre el comercio y la política: la trayectoria de Tomás Manuel Anchorena desde la Revolución de Mayo hasta su intervención en la Sala de Representantes de Buenos Aires”, Diego Fraccia parte de pensar el potencial que tiene el análisis de las trayectorias individuales en el marco de procesos más generales. Por ello, para reconstruir el recorrido de este actor, Fracchia parte de tener en cuenta sus vínculos familiares, comerciales y políticos, enmarcados en los procesos que los afectaron. Así, en análisis de la figura de Tomás Manuel Anchorena desde 1810 hasta su participación en la Sala de representantes de Buenos Aires en 1820 le permite mostrar cómo, en un marco de profunda politización de las distintas capas sociales, fue vinculándose paulatinamente con el poder político a pesar de sus cautelas.

La participación e intervención política también constituye el objeto de estudio de Mariano Di Pasquale en "Trayectorias de vida e inserción política de los médicos en Buenos Aires, 1820-1870". No obstante, el objetivo de Di Pasquale es indagar sobre las trayectorias de vida de ciertos médicos para dar cuenta que los cruces entre el mundo de la medicina y el de la política pueden ubicarse en una cronología anterior a la propuesta por historiografía local. Derivado de ello, el autor muestra la complejidad y la diversidad de situaciones que experimentaron los médicos en relación con espacio político y sus distintas modalidades de acceso al poder. En suma, sus experiencias y prácticas políticas a lo largo del siglo XIX permiten comprender cómo algunos médicos y, con ellos también, un discurso-saber médico obtenga una fuerte presencia en la toma de decisiones en el Estado-nacional argentino a partir de 1880.

Por último, el artículo "Entre la emoción y la intelectualización: la música como base de una sociología de la cultura de entre siglos" aborda el libro El lenguaje musical (1902) de José Ingenieros como un objeto discursivo que permite indagar en las tensiones de una época en tránsito, un clima de fin de siglo. A partir de ello, Nicolás Aliano y Guillermina Guillamon dan cuenta de cómo el texto cristaliza una doble tensión. Por un lado, una tensión intelectual respecto del análisis de lo musical y las aptitudes musicales, que péndula entre el determinismo biológico y la posibilidad de educación. Así, en el devenir del libro emergen y se despliegan un conjunto de tópicos que conforman esta estrategia: la simulación abordada desde la producción y el consumo cultural, las emociones intelectualizadas como herramienta para suavizar las costumbres y civilizar a los individuos, la identificación de indicadores visibles de incultura, entre otros. Derivado de ello, emerge otra tensión, que remite a una posición más amplia respecto de la cultura de entre siglos: aquella que, ambivalentemente, se configura entre estrategias por monopolizar la cultura y proyectos por construir hegemonía en torno a ella. 


\section{REFERENCIAS}

Bensa, A. (2015). De la microhistoria a una antropología crítica. En J. Revel (dir.) Juegos de escalas. Experiencias de microanálisis (pp. 45-86). Buenos Aires: UNSAM Edita.

Bourdieu, P. (2007) Las condiciones sociales de la circulación de las ideas. En P. Bourdieu, Intelectuales, politica y poder (pp. 159-172). Buenos Aires: Eudeba.

Burke, P. (2001). Hablar y Callar, Funciones sociales del lenguaje a través de la historia. Barcelona: Gedisa.

Chartier, R. (1992). El mundo como representación. Estudios sobre historia cultural. Barcelona: Gedisa.

Foucault, M. (2003). Las palabras y las cosas. Buenos Aires: Siglo XXI.

Foucault, M. (2005). La arqueología del saber. Buenos Aires: Siglo XXI.

Garzón Roge, M. (2017). Historia Pragmática. Una perspectiva sobre la acción, el contexto y las fuentes. Buenos Aires: Prometeo.

Deleuze, G. (1987). Foucault. Barcelona: Paidós.

Greville, J. y Pocock, A. (1971). Politics, Language, and Time. Essaysonpoliticalthought and history. Nueva York: Athenaeum.

Guinzburg, C. (2014). El hilo y las huellas. Lo verdadero, lo falso, lo ficticio. Buenos Aires: Fondo de Cultura Económica. Rosanvallon, P. (2002). Por una historia conceptual de lo politico. Buenos Aires: Fondo de Cultura Económica.

Shapin, S. y Schaffer, S. (2005). El Leviathan y la bomba de vacío. Hobbes, Boyle y la vida experimental. Bernal: Universidad Nacional de Quilmes.

Skinner, Q. (1986). Los fundamentos del pensamiento politico moderno. México: Fondo de Cultura Económica.

\section{Notas}

1 Sobre una reflexión desde la historiografía acerca del (re)surgimiento de la biografía y de la influencia de la "sociología de la acción” y del giro teórico y metodológico que ello conlleva, véase Morales Moya, 2008, pp. 91-100

2 Asimismo, la microhistoria ha reflexionado en torno a las limitaciones de las fuentes, específicamente sobre la mediación que supone la intervención de sujetos de la cultura dominante y que convierte a la fuente es un documento opaco, deformado. Pero aún en esta complejidad hay una certeza: de la cultura y de su condición social no escapa nadie. Derivado de este supuesto, se entiende que las fuentes ofrecen huellas, indicios que pueden constituir un hilo a través del cual reconstruir las experiencias y representaciones propias de las culturas populares. En este sentido, la propuesta del paradigma indiciario es expuesta en Guinzburg (2014). Específicamente véase la Introducción pp. 9-18) y el capítulo "El inquisidor como antropólogo", pp. 395-412. 